\title{
KOMUNITAS LAMUN DI PERAIRAN PANTAI DESA ORI, MALUKU TENGAH
}

\section{(Seagrass Community at Coastal Waters of Ori Village, Central Maluku)}

\author{
Sarah Haumahu ${ }^{1 *}$, Frijona F. Lokollo ${ }^{1}$ dan Reni Ambon ${ }^{2}$ \\ ${ }^{1}$ Jurusan Ilmu Kelautan Fakultas Perikanan dan Ilmu Kelautan Universitas Pattimura \\ ${ }^{2}$ Mahasiswa Program Studi Ilmu Kelautan Fakultas Perikanan dan Ilmu Kelautan Universitas Pattimura \\ shaumahu2@gmail.com,fflokollo1@gmail.com,renyambon1099@gmail.com \\ Corresponding author*
}

\begin{abstract}
ABSTRAK: Komunitas lamun memegang peranan penting di lingkungan laut dan daerah estuari, menyokong komunitas ikan, siput dan kerang-kerangan serta invertebrata lainnya. Keragaman spesies lamun di dunia sangat rendah ( $<60$ spesies). Perairan pantai Desa Ori memiliki komunitas lamun yang belum pernah diteliti. Tujuan dari penelitian ini adalah untuk mengestimasi struktur komunitas lamun di perairan pantai Desa Ori, Maluku Tengah yang meliputi komposisi jenis, kerapatan, frekuensi kehadiran dan persen penutupan. Pengambilan sampel lamun menggunakan metode transek garis. Lima spesies lamun ditemukan selama penelitian yang dikelompokan dalam dua famili yaitu famili Cymodoceaceae dan Hydrocharitaceae. Spesies-spesies lamun yang ditemukan adalah Cymodocea rotundata, Halodule pinifolia, Enhalus acoroides Halophila ovalis dan Thalassia hemprichii. T. hemprichii dan E. acoroides memiliki kerapatan tertinggi (masing-masing 157 tegakan $/ \mathrm{m}^{2}$ dan 137 tegakan $/ \mathrm{m}^{2}$ ). E. acoroides dan T. hemprichii juga memiliki frekuensi kehadiran serta persen penutupan relatif tertinggi dibanding spesies-spesies lamun lainnya yang ditemukan di perairan Desa Ori. Komunitas lamun di perairan Desa Ori tergolong dalam kondisi rapat sampai padat.
\end{abstract}

Kata Kunci: lamun, komunitas, kerapatan, penutupan, Maluku Tengah

ABSTRACT: Seagrass communities play an important role in marine environments and estuary area, supporting communities of fish, snails and shellfish and other invertebrates. The diversity of seagrass species in the world is very low ( $<60$ species). The coastal waters of Ori Village have a seagrass community that has never been studied. The purpose of this study was to estimate the structure of the seagrass community in the coastal waters of Ori Village, Central Maluku which includes the composition of type, density, frequency of occurence and percent of coverage. Seagrass sampling uses the line transect method. Five species of seagrass were found during the study grouped into two families: Cymodoceaceae and Hydrocharitaceae. The seagrass species found were Cymodocea rotundata, Halodule pinifolia, Enhalus acoroides Halophila ovalis and Thalassia hemprichii. T. hemprichii and E. acoroides have the highest densities (157 shoots $/ \mathrm{m}^{2}$ and 137 shoots $/ \mathrm{m}^{2}$, respectively). E. acoroides and T. hemprichii also have the highest frequency of occurence and relative coverage percent compared to other seagrass species found in the waters of Ori Village. Seagrass community in the waters of Ori Village is classified in a tight condition until dense.

Keywords: seagrass, community, density, coverage, Central Maluku 


\section{PENDAHULUAN}

Lamun adalah tumbuhan berbunga (Angiospermae) yang mampu beradaptasi terhadap kondisi lingkungan dekat pantai dari sebagian besar lautan di dunia yang dapat hidup di lingkungan laut sampai kedalaman $40 \mathrm{~m}$ (Dahuri, 2003; den Hartog \& Kuo, 2001). Padang lamun merupakan komponen penting di zona litoral. Komunitas lamun di daerah tropis merupakan ekosistem pantai yang sangat produktif dengan kekayaan fauna yang sangat tinggi serta merupakan ekosistem yang penting di dunia (Duarte, et al., 2012). Lamun berfungsi sebagai daerah pembesaran, daerah perlindungan dan daerah mencari makan bagi berbagai invertebrata dan ikan (Miftahudin, $d k k$., 2020). Selain itu, lamun adalah produser primer utama di habitat bentik (Short, et al., 2007; Jalaluddin, $d k k ., 2020)$.

Lamun memiliki penyebaran yang sangat luas di dunia baik di perairan tropis maupun perairan temperate (Kiswara\&Hutomo, 1985; Duffy, 2006; Parawansa, dkk., 2020). Lamun dapat hidup pada berbagai tipe substrat terutama substrat lunak di perairan dangkal di laut yang terlindung dan daerah estuari. Padang lamun dapat membentuk padang lamun tunggal (monospesifik) atau dapat membentuk padang lamun campuran, dimana dalam satu lokasi dapat ditemukan sekitar 12 spesies lamun. Tumbuhan lamun yang ditemukan di seluruh dunia sekitar 60 spesies yang dikelompokan dalam 13 genera dan 5 famili. Ada 20 spesies lamun ditemukan di wilayah Asia Tenggara dan 13 spesies ditemukan di Indonesia (den Hartog \& Kuo, 2001; McKenzie et al, 2007).

Beberapa penelitian tentang komunitas lamun telah dilakukan di perairan Maluku. Teridentifikasi enam jenis lamun yang tersebar di perairan Teluk Ambon Dalam (TAD), sehingga dapat dikatakan jenis lamun di TAD memiliki $46,2 \%$ dari jenis lamun yang ditemukan di seluruh perairan Indonesia (Irawan\&Nganro, 2016; Rugebregt, dkk., 2020). Perairan pesisir Negeri Suli memiliki komposisi jenis lamun sebanyak delapan jenis dengan nilai kerapatan berkisar antara 0,75-93,64 teg $/ \mathrm{m}^{2}$ (Sinmiasa, 2016).

Perairan pantai Desa Ori, Maluku Tengah memiliki adalah salah satu kawasan pesisir yang memiliki komunitas lamun yang cukup padat dan tersebar sepanjang pesisir pantai Desa Ori. Hal ini didukung oleh kondisi substrat yang menunjang pertumbuhan dan perkembangan tumbuhan lamun. Substrat pada perairan pantai Desa Ori terdiri atas substrat berlumpur, berpasir maupun substrat berbatu. Namun informasi tentang komunitas lamun terutama komposisi jenis, kerapatan, frekuensi kehadiran, dan persen penutupan jenis lamun pada perairan ini belum pernah diteliti dan tidak ada informasi yang tersedia tentang komunitas lamun di daerah ini. Dengan demikian, penelitian tentang komunitas lamun di pesisir Desa Ori Pulau Haruku, Maluku Tengah sangat penting untuk dilakukan dan menjadi data dasar bagi upaya pengelolaan nantinya. Tujuan dari penelitian ini yaitu untuk mengetahui komposisi spesies, kerapatan spesies frekuensi kehadiran, dan persen penutupan spesies lamun di perairan Desa Ori, Maluku Tengah.

\section{METODE PENELITIAN}

Penelitian ini dilakukan pada bulan Maret 2020 sampai bulan Juni 2020 di perairan Desa Ori, Pulau Haruku, Maluku Tengah (Gambar 1). Pengumpulan data lamun dilakukan secara langsung di lapangan dengan mengggunakan metode transect line (English, et al., 1997).

Pengambilan contoh lamun dilakukan pada saat surut dengan menggunakan kuadrat berukuran $0.5 \times 0.5 \mathrm{~m}$ yang dibagi atas 25 kotak (plot) dengan ukuran $0.01 \mathrm{~m}^{2}$. Jarak antar transek pengamatan sebesar $50 \mathrm{~m}$ dan jarak antar kuadrat adalah $5 \mathrm{~m}$. Lamun yang ada dalam setiap plot dihitung tegakan per spesies. Pengambilan sampel lamun dilakukan setelah perhitungan banyaknya tegakan lamun. Pengamatan terhadap persen penutupan lamun mengacu pada McKenzie, et al. (2007). Identifikasi lamun mengacu pada petunjuk Lanyon (1986). 


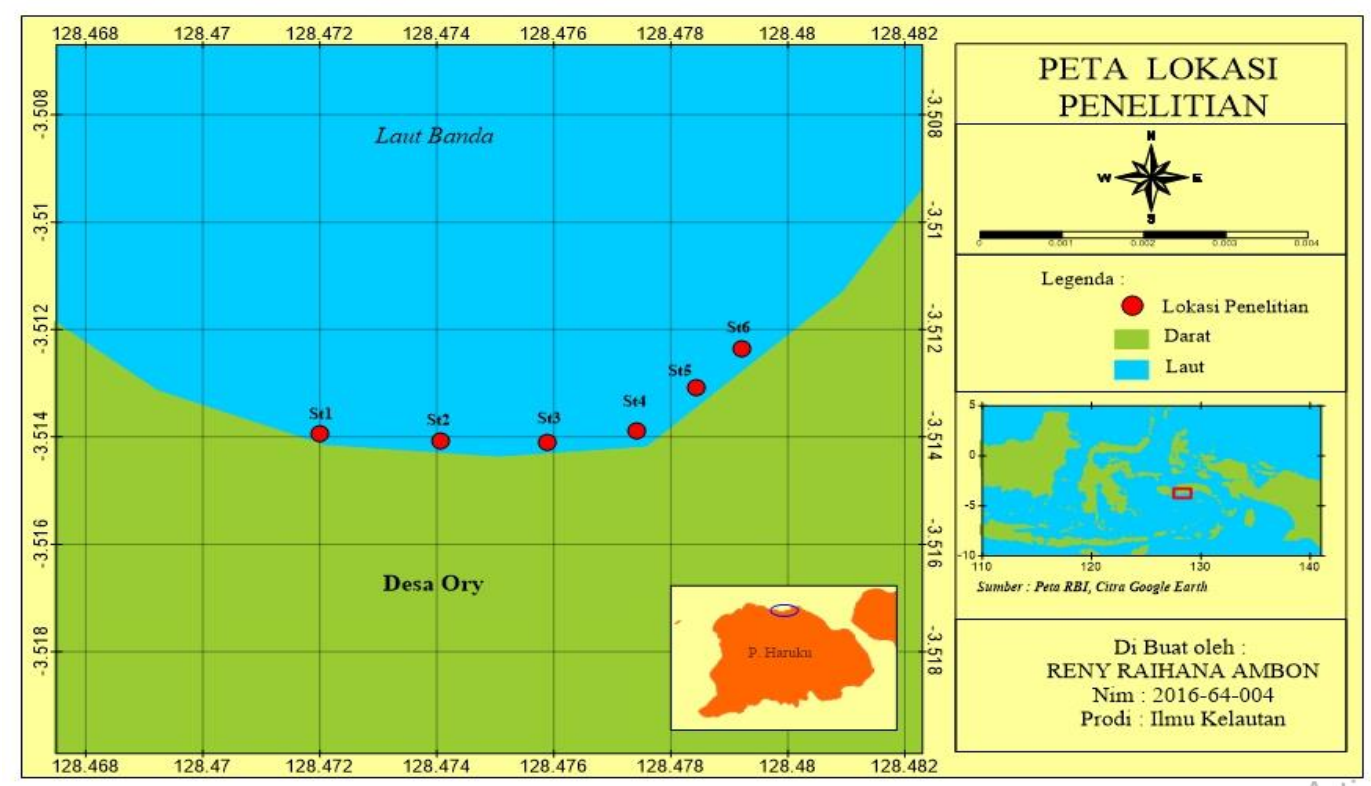

Gambar 1. Peta lokasi penelitian

Kerapatan setiap spesies pada setiap transek pengamatan dihitung dengan menggunakan formula menurut Dawes (1981) dan penentuan kondisi padang lamun menggunakan kriteria pada Tabel 1.

Keterangan:

$$
D i=\frac{N i}{A}
$$

$\mathrm{Di} \quad=$ Kerapatan spesies $\left(\right.$ tegakan $/ \mathrm{m}^{2}$ )

$\mathrm{Ni}=$ Jumlah total tegakan spesies

$\mathrm{A}=$ Total kuadrat pengamatan

Tabel 1. Skala kondisi lamun berdasarkan nilai kerapatan

\begin{tabular}{ccc}
\hline Skala & $\begin{array}{c}\text { Nilai kerapatan } \\
\left(\text { teg. } / \mathrm{m}^{2}\right)\end{array}$ & $\begin{array}{c}\text { Kondisi komunitas } \\
\text { lamun }\end{array}$ \\
\hline 5 & $>175$ & sangat rapat \\
4 & $125-175$ & rapat \\
3 & $75-125$ & agak rapat \\
2 & $25-75$ & jarang \\
1 & $1-25$ & sangat jarang \\
\hline
\end{tabular}

Kerapatan spesies relatif dihitung menggunakan formula menurut Dawes (1981):

Keterangan:

$$
R D i=\frac{D i}{\sum D n} \times 100
$$

$\mathrm{Di}=$ Kerapatan spesies-i

$\sum \mathrm{Dn}=$ Jumlah kerapatan seluruh spesies
$\mathrm{RDi}=$ Kerapatan spesies relatif $(\%)$

Frekuensi spesies dihitung dengan formula menurut Dawes (1981):

$$
\text { Frekuensi }=\frac{P i}{A}
$$

Keterangan:

$\mathrm{Fi} \quad=$ Frekuensi Jenis

$\mathrm{Pi}=$ Jumlah kuadrat dimana ditemukan spesies ke-i

A = Jumlah total kuadrat

Persen penutupan lamun ditentukan mengacu pada kriteria penutupan lamun (McKienzie, et al., 2007)

\section{HASIL DAN PEMBAHASAN}

\section{Komposisi Spesies Lamun}

Sebanyak lima spesies lamun ditemukan di perairan Desa Ori yang digolongkan dalam dua famili. Famili Hydrocharitaceae terdiri atas spesies Thalassia hemprichii, Enhalus accoroides, dan Halophila ovalis. Famili Cymodoceaceae terdiri atas dua spesies yaitu Cymodocea rotundata dan Halodule pinifolia. Tabel 2 menunjukan sebaran spesies lamun berdasarkan transek pengamatan. Hasil penelitian menunjukan bahwa hampir semua 
spesies lamun ditemukan pada semua transek pengamatan, kecuali spesies Cymodocea rotundata yang tidak ditemukan pada transek 3 dan 4. Hal ini berarti bahwa lamun Thalassia hemprichii, Enhalus acoroides, Halophila ovalis dan Halodule pinifolia memiliki penyebaran yang luas di perairan pantai Desa Ori. Empat spesies lamun ini umumnya ditemukan di semua tipe substrat pada lokasi penelitian.

Spesies T. hemprichii umumnya dijumpai berasosiasi dengan terumbu karang dan merupakan spesies lamun yang sangat umum di daerah rataan terumbu (Sakey, $d k k ., 2015$ ). Spesies E. acoroides mempunyai ukuran morfologi yang besar yang umum tumbuh di substrat lumpur. Spesies E. acoroides dapat tumbuh menjadi padang yang monospesifik ataupun seringkali tumbuh bersama dengan spesies lamun T. hemprichii (Short, et al., 2001, Irawan\&Nganro, 2016).

Jumlah spesies lamun yang ditemukan ini lebih rendah dibandingkan dengan jumlah spesies lamun yang ada di perairan Negeri Suli yang berada di perairan Kabupaten Maluku Tengah (Latuheru, 2011; Simiasa, 2016) yaitu delapan spesies lamun. Jumlah spesies lamun yang ditemukan di Desa Ori sama dengan jumlah spesies lamun yang ditemukan di perairan pantai Desa Waai yaitu lima spesies (Corputty, 2010). Perairan Pantai Negeri Tulehu Kabupaten Maluku Tengah juga memiliki komposisi jenis lamun sebanyak enam jenis (Payung\&Irawati, 2020). Perbedaan jumlah spesies ini disebabkan oleh perbedaan substrat dasar perairan. Setiap jenis lamun memiliki preferensi substrat masingmasing untuk pertumbuhannya (den Hartog, 1970; Waycott, et al., 2004). Substrat berperan penting bagi pertumbuhan lamun sebagai habitat hidup dan pemasok tersedianya nutrient (Yunitha, $d k k .$, 2014; Fahruddin, $d k k .$, 2017).

\section{Kerapatan Spesies Lamun}

Kerapatan jenis lamun dipengaruhi oleh jumlah tegakan suatu jenis lamun pada suatu luasan tertentu (Dawes, 1981). Nilai kerapatan lamun tertinggi di lokasi penelitian (Tabel 3) ditemukan pada spesies T. hemprichii berkisar antara 71-280 tegakan $/ \mathrm{m}^{2}$, rata-rata jumlah tegakan sebesar 157 tegakan $/ \mathrm{m}^{2}$, sedangkan kerapatan relatif berkisar antara 24.77-74.18\%. Kerapatan lamun jenis E. acoroides di lokasi penelitian berkisar antara $45-280$ tegakan $/ \mathrm{m}^{2}$ atau sekitar $13.20-72.17 \%$, dengan rata-rata jumlah tegakan 137 tegakan $/ \mathrm{m}^{2}$. Kerapatan spesies E. acoroides yang tinggi pada lokasi penelitian ini disebabkan perakaran lamun spesies ini yang kokoh dan menjalar pada permukaan substrat sehingga spesies ini mampu bertahan hidup dan berkembang dengan baik (Rahman, dkk., 2016; Wangkanusa, $d k k$., 2017). Spesies lamun lain umumnya memiliki struktur akar yang lebih kecil dan tidak sekokoh spesies E. acoroides.

Nilai kerapatan spesies lamun pada semua stasiun menunjukan bahwa spesies lamun $E$. acoroides dan $T$. hemprichii mempunyai nilai kerapatan spesies yang tidak berbeda. Hal ini disebabkan substrat pada semua transek pengamatan merupakan substrat yang cocok bagi kehidupan kedua spesies lamun tersebut terutama pada substrat lumpur berpasir. Spesies E. acoroides umumnya tumbuh di sedimen yang berpasir atau berlumpur serta dapat tumbuh menjadi padang lamun yang monospesifik. (Nienhuis, et al., 1989; Wangkanusa, dkk., 2017).

Tabel 2. Sebaran lamun berdasarkan transek pengamatan di perairan Pantai Desa Ori

\begin{tabular}{lcccccc}
\hline \multirow{2}{*}{ Spesies } & \multicolumn{7}{c}{ Kerapatan Spesies (teg/m $\left.{ }^{2}\right)$} \\
\cline { 2 - 7 } & Tr.1 & Tr.2 & Tr.3 & Tr.4 & Tr.5 & Tr.6 \\
\hline Enhalus acoroides & + & + & + & + & + & + \\
Halophila ovalis & + & + & + & + & + & + \\
Thalassia hemprichi & + & + & + & + & + & + \\
Cymodocea rotundata & + & + & - & - & + & + \\
Halophila pinifolia & + & + & + & + & + & + \\
\hline Ket: Tr=Transek & & & & & &
\end{tabular}


Spesies $H$. pinifolia memiliki nilai kerapatan terendah dibandingkan spesies lainnya yang ditemukan, karena rendahnya jumlah tegakan dari spesies lamun ini. Spesies ini umumnya ditemukan bertumbuh pada substrat pasir atau lumpur berpasir (den Hartog dan Kuo, 2001). Sebagian besar kondisi substrat pada lokasi penelitian di perairan Desa Ori berupa pasir dengan pecahan karang dan batu sehingga kondisi substrat tersebut kurang sesuai untuk mendukung pertumbuhan lamun spesies $H$. pinifolia. Secara keseluruhan dapat dikatakan kondisi komunitas lamun di perairan pantai Desa Ori tergolong dalam kategori rapat dengan jumlah tegakan rata-rata untuk $E$. acoroides dan T. hemprichii masing-masing 137 tegakan $/ \mathrm{m}^{2}$ dan 157 tegakan $/ \mathrm{m}^{2}$.

\section{Frekuensi Kehadiran Relatif}

Frekuensi dari suatu spesies lamun menunjukan derajat penyebaran spesies lamun tersebut dalam komunitas. Secara umum, spesies lamun dengan frekuensi kehadiran relatif tertinggi yang ditemukan pada perairan Desa Ori adalah spesies E. acoroides $(27.04 \%)$ dan $T$. hemprichii (25.60\%) (Tabel 4). Hal ini berarti bahwa sekitar 26-28\% kedua jenis lamun ini dapat ditemukan di perairan Desa Ori.

Spesies E. acoroides memiliki penyebaran tertinggi pada perairan Desa Ori. Nybakken (2001) menyatakan bahwa spesies lamun $E$. acoroides mempunyai kecepatan pertumbuhan yang lebih tinggi dibandingkan dengan spesies lainnya, sehingga diduga kehadiran E. acoroides ada kaitannya dengan kemampuan tumbuh spesies lamun ini. Selain itu, tingginya nilai frekuensi kehadiran dari spesies E. acoroides dipengaruhi oleh sifatnya yang eurycious yaitu mempunyai kemampuan hidup di lokasi manapun (Tomascik, et al, 1997; Parawansa, $d k k$. , 2020). Tingginya frekuensi kehadiran spesies E. acoroides menunjukan spesies ini dapat menyesuaikan diri dengan karakteristik habitat perairan Desa Ori. Menurut den Hartog (1970) menyatakan bahwa spesies lamun magnozosterid (lamun dengan bentuk daun yang panjang dan menyerupai pita dengan daun yang tidak terlalu lebar) dapat dijumpai pada berbagai habitat. Spesies lamun ini sering ditemukan di daerah dangkal hingga daerah surut.

\section{Persen Penutupan Lamun}

Penutupan lamun menggambarkan tingkat penutupan atau penaungan ruang oleh komunitas lamun. Secara umum terlihat bahwa spesies $E$. acoroides memiliki persen penutupan lamun yang lebih tinggi dibanding spesies lamun lainnya $(50.24 \%)$ diikuti oleh spesies $T$. hemprichii (47.23\%) (Tabel 5). Kedua spesies lamun ini menyebar di seluruh kuadrat pengamatan. E. acoroides dan $T$. hemprichii memiliki nilai penutupan yang lebih tinggi karena ukuran daunnya yang lebih besar dan panjang. Sebaliknya $H$. ovalis dan $H$. pinifolia yang berukuran lebih kecil dengan ukuran daunnya yang kecil memiliki nilai persentase penutupan yang lebih kecil pula (Sakey, $d k k$., 2015; Ansal, $d k k$., 2017). Kerapatan yang tinggi dan kondisi pasang surut saat pengamatan juga dapat mempengaruhi nilai estimasi penutupan lamun (Fahruddin, $d k k .$, 2017).

Tabel 3. Kerapatan dan kerapatan relatif spesies lamun di perairan Pantai Desa Ori

\begin{tabular}{lcccccccccccc}
\hline \multirow{2}{*}{ Famili/Spesies } & \multicolumn{4}{c}{ Kerapatan Spesies $\left(\mathrm{teg} / \mathrm{m}^{2}\right)$} & \multicolumn{4}{c}{ Kerapatan Spesies Relatif $(\%)$} \\
\cline { 2 - 14 } & Tr.1 & Tr.2 & Tr.3 & Tr.4 & Tr.5 & Tr.6 & Tr.1 & Tr.2 & Tr.3 & Tr.4 & Tr.5 & Tr.6 \\
\hline C. rotundata & 39 & 21 & 0 & 0 & 2 & 6 & 9.44 & 6.02 & 0 & 0 & 0.85 & 1.89 \\
H. pinifolia & 19 & 11 & 8 & 3 & 8 & 3 & 4.76 & 3.1 & 2.61 & 0.98 & 2.82 & 1.09 \\
E. acoroides & 55 & 45 & 191 & 208 & 170 & 151 & 13.38 & 13.2 & 63.86 & 72.17 & 59.22 & 49.13 \\
H. ovalis & 17 & 12 & 8 & 6 & 7 & 6 & 4.09 & 3.5 & 2.64 & 2.08 & 2.59 & 1.8 \\
T. hemprichi & 280 & 254 & 92 & 71 & 99 & 142 & 68.33 & 74.18 & 30.88 & 24.77 & 34.51 & 49.09 \\
\hline
\end{tabular}


Tabel 4. Frekuensi kehadiran relatif lamun di perairan Pantai Desa Ori

\begin{tabular}{lccccccc}
\hline \multirow{2}{*}{ Spesies } & \multicolumn{9}{c}{ Frekuensi Kehadiran Relatif $(\%)$} & \multirow{2}{*}{ Rataan } \\
\cline { 2 - 7 } & Tr.1 & Tr.2 & Tr.3 & Tr.4 & Tr.5 & Tr.6 & \\
\hline C.rotundata & 24.39 & 20.51 & 0.00 & 0 & 20.05 & 21.66 & 14.44 \\
H. pinifolia & 13.41 & 15.45 & 26.02 & 22.5 & 25.00 & 21.66 & 20.67 \\
E. acoroides & 22.20 & 20.51 & 33.33 & 36.5 & 20.05 & 29.67 & 27.04 \\
H. ovalis & 15.61 & 17.98 & 10.98 & 13.5 & 7.42 & 8.01 & 12.25 \\
T. hemprichi & 24.39 & 25.56 & 29.67 & 27.5 & 27.47 & 18.99 & 25.60 \\
\hline
\end{tabular}

Tabel 5. Persentase penutupan relatif lamun di perairan Pantai Desa Ori

\begin{tabular}{|c|c|c|c|c|c|c|c|}
\hline \multirow{2}{*}{ Spesies } & \multicolumn{6}{|c|}{ Persentase penutupan (\%) } & \multirow{2}{*}{ Rataan (\%) } \\
\hline & Tr.1 & Tr.2 & Tr.3 & Tr.4 & Tr.5 & Tr.6 & \\
\hline C. rotundata & 3.90 & 0.75 & 0.00 & 0.00 & 0.73 & 0.74 & 1.02 \\
\hline H. pinifolia & 0.57 & 0.75 & 0.64 & 0.46 & 1.45 & 0.74 & 0.77 \\
\hline E. acoroides & 8.04 & 16.85 & 72.08 & 71.82 & 70.26 & 62.38 & 50.24 \\
\hline H. ovalis & 0.80 & 0.66 & 0.73 & 0.55 & 0.92 & 0.74 & 0.73 \\
\hline T. hemprichi & 86.68 & 80.99 & 26.54 & 27.16 & 26.64 & 35.38 & 47.23 \\
\hline
\end{tabular}

\section{KESIMPULAN DAN SARAN}

Lima spesies lamun ditemukan di perairan pantai desa Ori yaitu Cymodocea rotundata, Halodule pinifolia, Enhalus acoroides, Halophila ovalis dan Thalassia hemprichii. Spesies T. hemprichii memiliki kerapatan tertinggi (157 tegakan $\left./ \mathrm{m}^{2}\right)$ dan E. acoroides memiliki kerapatan kedua tertinggi (137 tegakan $\left./ \mathrm{m}^{2}\right)$. E. acoroides dan T. hemprichii juga memiliki frekuensi kehadiran serta persen penutupan relatif tertinggi dibanding spesiesspesies lamun lainnya yang ditemukan di perairan Desa Ori. Komunitas lamun di perairan Desa Ori tergolong dalam kondisi rapat hingga padat.

Perlu dilakukan penelitian lanjutan tentang sebaran lamun berdasarkan tipe substrat sehingga dapat memperoleh informasi yang lebih akurat tentang pola penyebaran lamun di perairan Desa Ori.

\section{DAFTAR PUSTAKA}

Ansal, M.H., D. Priosambodo, M. Litaay, M.A. Salam. 2017. Struktur Komunitas Padang Lamun di Perairan Kepulauan Waisai Kabupaten Raja Ampat Papua Barat. Jurnal Ilmu Alam dan Lingkungan 8(15): 29-37.

Corputty, M. 2010. Struktur Komunitas Lamun pada Perairan Pantai Desa Waai, Kecamatan Salahutu. Skripsi. Fakultas Perikanan dan Ilmu Kelautan, Universitas Pattimura, Ambon.
Dahuri, R. 2003. Keanekaragaman Hayati Laut Aset Pembangunan Berkelanjutan Indonesia. Penerbit Gramedia Pustaka Utama. Jakarta.

Dawes, C.J. 1981. Marine Botany. A WileyIntersciense Publication. John Wiley \& Sons. New York. 628p.

den Hartog, C. \& Kuo, J. 2001 Seagrass Taxonomy and Identification Key. Global Seagrass Reseach Methods. Chapter 2: 31-58.

den Hartog, C. 1970. The Seagrasses of The World. North Holland Publishing Co., Amsterdams.

Duarte, M.C., Bandeira, S., Romeiras, M. M. 2012. Systematics and Ecology of a New Species of Seagrass (Thalassodendron, Cymodoceaceae) from Southeast African Coast. BioOne Recearch Evolve 22:16-24. Doi: http://dx.doi.org/10.3417/2010079.

Duffy. J.E. 2006. Biodiversity and the Functioning of Seagrass Ecosystems. Marine Ecological Progress Series. 311: 233-250.

English S, Wilkinson C, Baker V. 1997. Survey Mannual for Tropical Marine Resource. Australia: ASEAN-Australian.

Fahruddin, M., F. Yulianda, I. Setyobudiandi. 2017. Kerapatan dan Penutupan Ekosistem Lamun di Pesisir Desa Bahoi, Sulawesi Utara. Jurnal Ilmu dan Teknologi Kelautan Tropis 9(1): 375-383.

Irawan, A \& N.R. Nganro. 2016. Sebaran Lamun di Teluk Ambon Dalam. Jurnal Ilmu dan Teknologi Kelautan Tropis 8(1): 99-114.

Jalaluddin, M., I.N. Octaviyani, A.N.P. Putri, W. Octaviyani, I. Aldiansyah. 2020. Padang Lamun Sebagai Ekosistem Penunjang Kehidupan Biota Laut di Pulau Pramuka, Kepulauan Seribu, Indonesia. Jurnal Geografi Gea 20(1): 44-53. 
Kiswara, W. \& M. Hutomo. 1985. Habitat dan Sebaran Geografik Lamun. Oseana X(1): 2130.

Lanyon, J. 1986. Seagrasses of The Great Barrier Reef Region: Guide to The Identification of Seagrasses in The Great Barrier Reef Region. Great Barrier Reef Marine Park Authority. Queensland.61p.

Latuheru, N. 2011. Distribusi Lamun Berdasarkan Ukuran Butiran Sedimen Pada Perairan Pantai Desa Suli. Skripsi Fakultas Perikanan dan Ilmu Kelautan Universitas Pattimura, Ambon.

McKenzie, L.J., Yaakub, S.M., Yoshida, R.L. 2007. Seagrass-Watch: Guidelines for TeamSeagrass Singapore Participants. Proceedings of a Training Workshop, National Parks Board, Biodiversity Centre, Singapore, $24^{\text {th }}-25^{\text {th }}$ March 2007 (DPI\&F, Cairns). 32pp.

Miftahudin, M.F., Muzani, B. hardianto, N.P. Ramadhita, S. Widyarini. 2020. Pengaruh Lamun (Seagrass) Terhadap Kehidupan Ikan di Perairan Pulau Pramuka, Kepulauan Seribu. Jurnal geografi: Geografi dan Pengajarannya XVIII(1): 27-42.

Nienhuis, P.H., Coosen, J., Kiswara, W. 1989. Community Structure and Biomass. Nederlands Journal of Sea Research 23(2): 197-214.

Nybakken, J.W. 2001. Marine Biology, an Ecological Approach. Bunjamin Cumming Inprint. 516 p.

Parawansa, B.S., I.F. Ningsih, S.B.A. Omar. 2020. Biodiversitas Lamun di Perairan Kepulauan Tonyaman, Kabupaten Polewali Mandar. Prosiding Simposium Nasional VII Kelautan dan Perikanan. Fakultas Ilmu Kelautan dan Perikanan, Universitas Hasanuddin, Makassar. ISBN 978-602-71759-7-6.

Payung, D. \& Irawati. 2020. Prakiraan Dampak Aktivitas Masyarakat Terhadap Komunitas Lamun di Perairan Pantai Negeri Tulehu Kecamatan Salahutu Kabupaten Maluku Tengah. Biopendix: Jurnal Biologi Pendidikan dan Terapan 7(1): 1-12.
Rahman, A.A., A.I. Nur, M. Ramli. 2016. Studi Laju Pertumbuhan Lamun (Enhalus acoroides) di Perairan Pantai Desa Tanjung Tiram Kabupaten Konawe Selatan. Sapa Laut 1(1): 10-16.

Rugebregt, M.J., Matuanakotta, C., Syafrizal. 2020. Keanekaragaman Jenis, Tutupan Lamun, dan Kualitas Air di Teluk Ambon. Jurnal Ilmu Lingkungan 18(3): 589-594, doi:10.14710/jil.18.3.589-594.

Sakey, W.F., B. T. Wagey, G. S. Gerung. 2015. Variasi Morfometrik Pada Beberapa Lamun di Perairan Semenanjung Minahasa. Jurnal Pesisir dan Laut Tropis 1(1): 1-7.

Short, F, Carruthers, T., Dennison, W., Waycott, M. 2007. Global Seagrass Distribution and Bioversity: a Bioregional Model. Journal of Experimental Marine Biology and Ecology. 350: 3-20.

Sinmiasa, V.C. 2016. Kajian Aspek Bioekologis Komunitas Lamun di Perairan Pesisir Negeri Suli, Maluku Tengah. TRITON: Jurnal Manajemen Sumberdaya Perairan 12(1): 3135.

Tomascik, T., Mah, A. J., Nontji, A., Moosa, M. K. 1997. The Ecology of The Indonesian Sea Volume 8 Part 2. Oxford University Press. Dalhausie pp: 829-906.

Wangkanusa, M.S., K.I.F. Kondoy, A.B. Rondonuwu. 2017. Identifikasi Kerapatan dan Karakter Morfometrik Lamun Enhalus acoroides Pada Substrat yang Berbeda di Pantai Tongkeina Kota Manado. Jurnal Ilmiah Platax 5(2): 210-220.

Waycott, M., McMahon, K., Mellosr, J., Calladine, A., Kleine, D. 2004. A Guide to Tropical Seagrass of The Indo-west Pacific. James Cook University Press. Townsville.

Yunitha, A., Y. Wardianto, F. Yulianda. 2014. Diameter Substrat dan Jenis Lamun di Pesisir Bahoi Minahasa Utara: Sebuah Analisis Korelasi. Jurnal Ilmu Pertanian Indonesia 19(3): 130-135. 